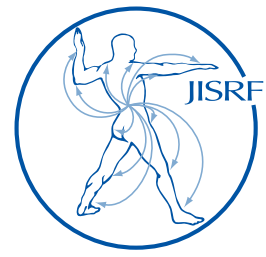

Check for updates

\title{
Short-Stem Hip Arthroplasty as a Solution for Limited Proximal Femoral Bone Stock
}

\author{
Gamboa $A^{1}$, Campbell $D^{1}$, Lewis $P^{1}$
}

Keywords: Total hip arthroplasty, Short stem prosthesis

Level of Evidence: AAOS Therapeutic Level IV

\section{Introduction}

Achieving stable fixation in total hip arthroplasty (THA) in the presence of limited proximal femoral bone stock is a frequent challenge in the revision setting but less common for primary hip arthroplasty. We describe an uncommon scenario in which options for femoral fixation of a primary hip arthroplasty were limited as the femoral diaphysis was almost completely filled by a long stemmed revision knee replacement.

Conventional hip arthroplasty components have historically used stems greater than $150 \mathrm{~mm}$ [5]. Several companies have introduced shorter versions of a conventional stem design with lengths less than $150 \mathrm{~mm}$ [1]. These are popular in Asian races of short stature who often have a narrow femoral diaphysis and curved femurs that conflict with traditional length stems. Hip resurfacing and metaphyseal stems that do not enter the diaphysis, are design alternatives to conventional stems. Metaphyseal stems are short curved designs that preserve some of the calcar femoralis and attempt to load the proximal femur in a more physiological manner $[3,12]$. Short stems and resurfacing implants have an occasional indication for treating hip joint pathology associated with femoral deformity such as after femur malunion or osteotomy [14]. The described case highlights the conflict of insufficient diaphysis available for hip implant fixation.

\section{Case Presentation}

A 63 year old female presented with incapacitating bi- lateral hip pain. She had significant co-morbidities which included rheumatoid arthritis, steroid induced osteoporosis, and diabetes. Her Charnley grading was C. She had bilateral primary total knee arthroplasty three years prior to presentation. One year following her primary knee arthroplasties, she sustained bilateral distal femoral fractures after a fall that were managed by revision knee arthroplasties. Her left knee revision had a long stemmed condylar femoral prosthesis while the right was revised with a very long stemmed condylar femoral prosthesis that ended $10 \mathrm{~cm}$ from the lesser trochanter. This was combined with a strut allograft.

At presentation she was able to ambulate minimally with a frame. Her presenting problem was incapacitating bilateral trochanteric and groin pain, with deteriorating weight-bearing capability and rest pain. Physical examination showed a frail patient with a crouched stance and a support-dependant stiff-hip antalgic gait. Both hips had audible crepitus on movement, fixed flexion deformities with limited flexion and no rotation. Her right knee had a range of motion of 35 - 80 degrees and her left knee $35-85$ degrees. Her initial radiographs showed bilateral cemented revision knee arthroplasties that filled most of the femoral diaphyses. There was also severe generalised osteopenia

1 The Wakefield Orthopaedic Clinic, 270 Wakefield Steet, Adelaide 5000, South Australia, AU tive Review follows the Creative Commons Attribution-NonCommercial CC BY-NC. This license allows anyone to download works, build upon the material, and share them with others for non-commercial purposes as long as they credit the senior author, Reconstructive Review, and the Joint Implant Surgery \& Research Foundation (JISRF). An example credit would be: "Courtesy of (senior author's name), Reconstructive Review, JISRF, Chagrin Falls, Ohio". 

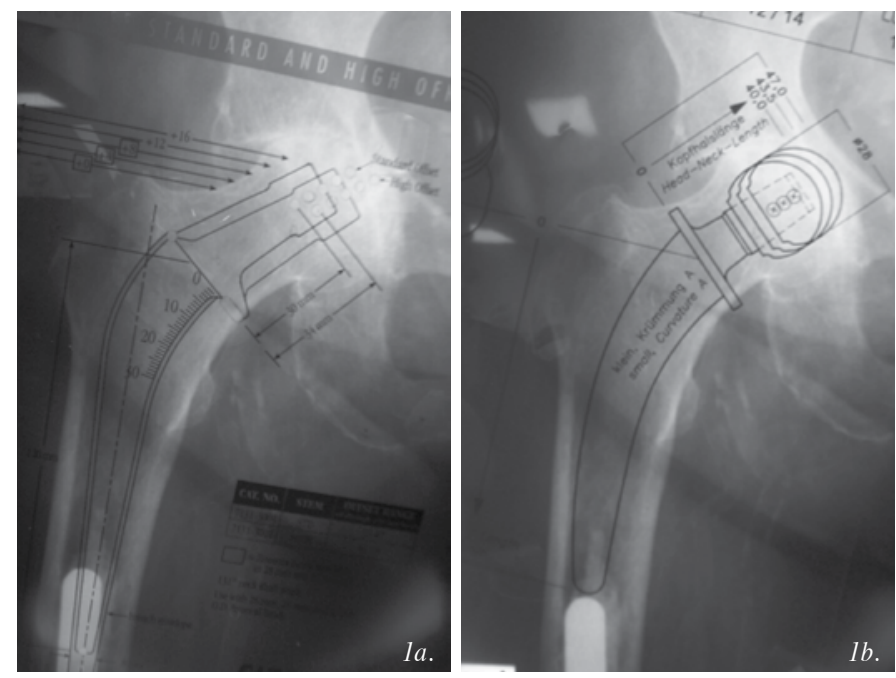

Figure 1: Radiographs showing limited proximal bone on the right.

1a. Preoperative templating with a stem of conventional length overlying a longstemmed revision knee component.

1b. Preoperative templating with a short stem femoral prosthesis

with rheumatoid changes in both hips including protrusio acetabuli and complete chondral space loss.

Preoperative templating showed that a prosthesis of traditional stem length could not be accommodated due to the stemmed knee component (Figure 1) and therefore a shorter neck-preserving implant was selected.

The patient underwent a right total hip arthroplasty using a posterior approach. A LINK ${ }^{\circledR}$ TOP cementless acetabular cup and $\mathrm{CFP}^{\circledR}$ (Collum Femoris Preserving) short stem were used (Waldemar Link GmbH \& CO, Hamburg, Germany) with intentional lengthening of $15 \mathrm{~mm}$ to restore her premorbid length. Six weeks postoperatively she had a marked improvement in right hip function with no pain, and an improved range of motion. She had persisting difficulty in ambulating due to the left hip pain and stiffness. The left hip was then replaced three months following her right hip surgery with the same implant type and sizes. No post-operative complications were observed.

At one year she reported an improvement in her quality of life and was observed to be ambulating faster with a frame in a more erect position. At five years and eleven years post-surgery she was very content with her hips, and also felt that she had improved knee motion which was attributed to the resolution of the pre-operative hip flexion deformities that had induced her crouched posture. Serial radiographs at one year, five years and eleven years demonstrated stable implants (Figure 2).

\section{Discussion}

The femoral component of a total hip replacement (THR) serves an essential role in transmitting the forces
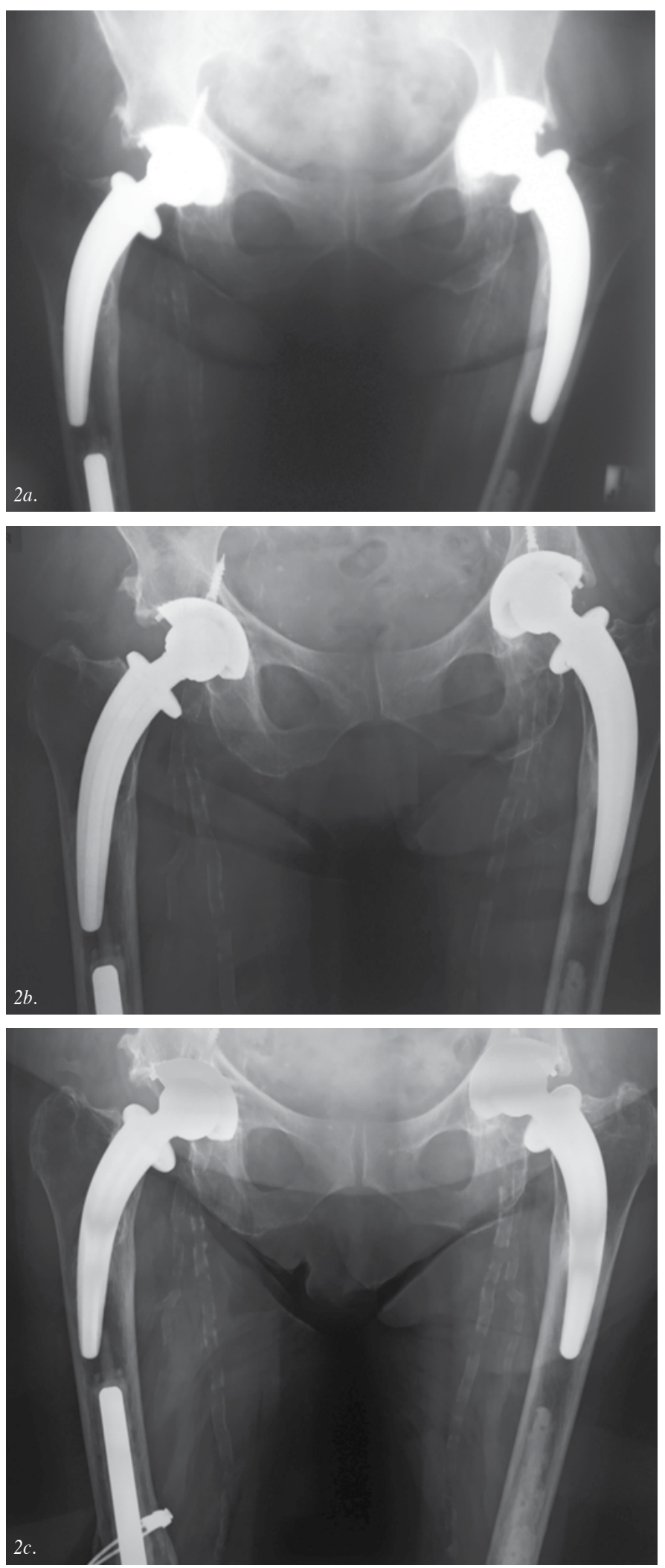

Figure 2: Bilateral total hip arthroplasties with uncemented short stem prostheses proximal to long stemmed revision knee components. Calcar resorption and proximal diaphyseal hypertrophy progresses to eleven years post surgery.

$2 a$. One year post Operative.

$2 b .5$ years post operative.

2c. Eleven years post operative. 
generated at the centre of rotation to the proximal femur. The femoral component historically has a segment that engaged the femoral diaphysis and a variety of lengths have been used $[6,8,17,18]$. Short stems were initially designed to achieve a more anatomical pattern of stress distribution by loading the femur proximally. Short stems claim several potential advantages which include reducing proximal stress shielding and bone resorption as well as thigh pain, [7] eliminating femoral proximal-distal mismatch, soft and hard tissue preservation, enhanced proximal bone remodeling, less blood loss, shortened postoperative rehabilitation and recovery, minimized instrumentation, fewer inventory costs and simplified femoral revisions. $[4,9,13]$

A number of classification systems for the short stem have been proposed $[3,6,11]$ mostly based on the stem length, intended site of primary stability, and level of osteotomy. The JISRF $[9,10]$ classification of stems includes four categories; 1) Head stabilized 2) Neck stabilized 3) Metaphyseal stabilized and 4) Conventional (Metaphyseal/ Diaphyseal) stabilized. The LINK $^{\circledR}$ CFP (Collum Femoris Preserving) prosthesis is a type 2 or "neck stabilized" short stem. It is an uncemented short stem prosthesis that preserves the femoral neck and proximal cancellous bone. It was primarily developed for biologically young and active patients. Pipino et al, who developed the CFP short stem, reported excellent (82\%) clinical mid-term results [15]. At 25 years [16] he reported 97\% 'good' clinico-radiographic outcomes and a survival rate of almost $100 \%$. He proposed that preserving "healthy" tissue, which includes the femoral neck, has the advantage of maintaining the osteoarticular architecture that would maximize mechanical stability and optimize distribution of mechanical loads, which will then favour enhanced osteointegration and bone remodelling.

This patient was neither young nor active, and had osteoporosis which are all relative contra-indications for a neck preserving short stem prosthesis. The decision to use a short stemmed implant in this patient was a controversial decision made after consideration of her limited and high risk options. She had undergone previous bilateral revision knee arthroplasties and the long stems of her femoral components had consumed most of the femoral diaphysis. This case emphasizes the importance of pre-operative templating which clearly showed that the use of a stem of conventional length was not possible. The alternate surgical option was to also revise her functioning long-stemmed knee components, which could even lead on to total femoral replacements. Acknowledging the relative contraindications associated with her suboptimal bone quality it was elected to proceed with a less invasive surgical option and use a short stemmed press-fit device.

\section{Conclusion}

This case emphasizes the importance of preoperative templating as an important part of pre-operative planning [2]. Confronted with limited high risk options, this case also demonstrates the successful use of a short-stemmed device to permit hip arthroplasty in the presence of inadequate femoral bone stock as a consequence of previous surgery or deformity.

\section{Disclosure Statement:}

The authors of this article have declared there is no potential for conflict of interest and no benefits or funds were received in support of this paper. For full disclosures refer to last page of this journal.

\section{References}

1. Briem D, Scneider M, Bogner N, Botha N, Gebauer M, Gehrke T, Schwantes B. Midterm Results of 155 patients treated with a collum femoris preserving (CFP) short stem prosthesis. International Orthopaedics (SICOT) (2011) 35;655-660

2. Eggli S, Pisan M, Muller ME. The Value of preoperative planning for Total hip arthroplasty. J Bone Joint Surg Br 1998; 80 (3); 382-390

3. Feyen H, Shimmin AJ. Is the length of the femoral component important in primary total hip replacement? Bone Joint J 2014;96-B:442-8

4. Goosen JHM, Van Hellemondt G. Primary THA with a retained intramedullary femoral nail. Acta Orthop Belg, 2013, 79: 114-116

5. Keisu KS, Orozco F, McCallum JD III, Bisset G, Hozack W, Sharkey P, Rothman R. Cementless femoral fixation in the Rheumatoid Patient undergoing Total Hip Arthroplasty: Minimum 5 year results. The Journal of Arthroplasty Vol.16 No.4 2001

6. Khanuja HS, Banerjee S, Jain D, Pivec R, Mont MA. Short Bone-Conserving Stems in Cementless Hip Arthroplasty. J Bone Joint Sur Am 2014 Oct15;96 (20);1742-1752

7. Kim YH, Kim JS, Cho SH. Strain distribution in the proximal human femur: An in vitro comparison in the intact femur and after insertion of reference and experimental femoral stems. J Bone Joint Surg (Br) 2001;83-B:295-301

8. Kim YH, Park JW, Kim JS. Is Diaphyseal stem fixation necessary for primary total hip arthroplasty in patients with osteoporotic bone (Class $\mathrm{C}$ bone)? The Journal of Arthroplasty Vol. 28 No.1 January 2013

9. McTighe T, Stulberg SD, Keppler L, Keggi J, Kennon RT, Brazil D, Aram T, McPherson E, \&TSITM Study Group Members. Joint Implant Surgery \& Research Foundation (JISRF) Classification System for Short Stem Uncemented THA. TSITM Study Group September 2012

10. McTighe T, Stulberg SD, Keppler L, Keggi J, Kennon RT, Brazil D, Aram T, McPherson E. A Classification System for Short Stem Uncemented Total Hip Arthroplasty. Bone Joint J 2013 vol 95-B no.SUPP 15260

11. Mont MA, McGrath MS, Ulrich SD. Metal on Metal total hip resurfacing arthroplasty in presence of extra-articular deformities or implants. J Bone Joint Surg 2008; 90-A: $45-57$

12. Mont MA, Pivec R, Kimona I, Harwin S. Short stem option for total hip arthroplasty with retained hardware. Orthopedics 36.10 (Oct 2013) 770-2

13. Patel RM, Smith MC, Woodward CC, Stulberg SD. Stable fixation of short stem femoral implants in patients 70 years and older. Clin Orthop Relat Res (2012) 470:442-449

14. Patel RM, Stulberg SD. The Rationale for short uncemented stems in total hip arthroplasty. Orthop Clin N Am 45 (2014) 19-31

15. Pipino F, Keller A. Tissue-sparing surgery: 25 years' experience with femoral neck preserving hip arthroplasty. J.Orthopaedics and Traumatology 2006 7:36-41

16. Pipino F, Molfetta L, Grandizio M. Preservation of the femoral neck in hip arthroplasty: results of a 13- to 17 year follow up. J Orthopaedics and Traumatology 200 1:31-39

17. Schmidutz F, Beirer M, Weber P, Mazoochian F, Fottner A, Jansson V. Biomechanical reconstruction of the hip: comparison between modular short stem hip arthroplasty and conventional total hip arthroplasty. International Orthopaedics (SICOT) (2012) 36:1341-1347

18. Stulberg SD, Patel RM. The Short stem: Promises and Pitfalls. Bone Joint J 2013;95-B, SuppleA:57-62 